\title{
Distribuição espacial da hotelaria de rede no estado do Paraná (Brasil)
}

\section{Hotel chains spatial distribution in Paraná state (Brazil)}

\author{
Daniel Raminelli Píccolo (PÍCCOLO, D. R.) \\ José Manoel Gonçalves Gândara (GÂANARA, J. M. G.) ${ }^{* *}$
}

\begin{abstract}
RESUMO - O presente artigo tem por objetivo analisar a distribuição espacial das redes de hotéis que atuam no Paraná (Brasil). Foram realizadas uma revisão bibliográfica e leituras pertinentes à temática, além da busca de dados referentes à demanda turística dos municípios do recorte espacial da pesquisa através do banco de dados da Secretaria de Turismo do Estado do Paraná (SETU) e do levantamento das redes de hotéis que atuam no Estado através do Guia 4 Rodas (2010), da editora Abril. Os dados foram sistematizados e analisados através da confecção de tabelas e cartogramas. Com o crescimento do turismo de negócios na capital paranaense e em cidades do interior, como, por exemplo, Londrina e Maringá, há uma atração de redes de hotéis que atendem aos chamados homens de negócios. Observa-se que há uma concentração de redes nos principais destinos do Estado, bem como na cidade de Foz do Iguaçu, que atrai turistas que viajam a lazer.
\end{abstract}

Palavras-Chave: Distribuição espacial; Hotelaria de rede; Demanda turística; Paraná.

ABSTRACT - The present study aims to analyze the spatial distribution of hotel chains in Paraná (State of Brazil). A bibliographical research concerning this subject was carried out and it was searched data related to the tourism demand in towns, from the research spatial portion, using the data bank of the Paraná Secretary of Tourism (SETU) and of the collection of names of hotel chains present in Parana, quoted in the guide Guia 4 Rodas, published by Editora Abril. The data were systematized and analyzed by tables and cartograms. As business tourism increases in Paraná capital city (Curitiba) as well as in towns, such as Londrina and Maringa, hotel chains are attracted to serve the claim of businessmen. It was observed that there is a concentration of hotel chains in the main destinations of the state, as well as Foz do Iguaçu, which attracts tourists traveling for pleasure.

Keywords: Spatial distribution; Hotel chains; Tourist demand; Paraná.

\footnotetext{
* Graduação em Geografia (Licenciatura e Bacharelado) pela Universidade Estadual de Maringá (UEM) e Mestrado em Geografia pelo Programa de Pós-Graduação em Geografia da Universidade Federal do Paraná (UFPR). Professor da rede pública de ensino do Estado do Paraná. Endereço para correspondência: Rua Dr. Faivre, 405 ( $3^{\circ}$ andar). CEP: 80060-140 - Curitiba - Paraná (Brasil). Telefone: 41 3360-5231. E-mail: danielpiccolo@ymail.com

** Graduação em Turismo pela UFPR, Especialização em Marketing Internacional pela SIOI de Roma e em Economia do Turismo pela Universidade Bocconi de Milão, Mestrado em Gestão do Turismo pela SSCTS de Milão e Doutorado em Turismo e Desenvolvimento Sustentável pela Universidade de Las Palmas de Gran Canaria. Pósdoutorados em sustentabilidade, qualidade, marketing, recursos humanos, termalismo, planejamento e gestão de destinos turísticos e hotéis nas Universidades de Alicante, Las Palmas, Málaga, Valencia e Vigo, onde é professor, pesquisador e orientador convidado nos respectivos Mestrados e Doutorados em Turismo. Professor e pesquisador do Departamento de Turismo da UFPR, ministrando aulas e orientando no curso de Graduação em Turismo, na Especialização em Planejamento e Gestão do Turismo e no Mestrado e Doutorado em Geografia. Coeditor da CULTUR - Revista de Cultura e Turismo. Endereço para correspondência: Rua Dr. Faivre, 405 ( ${ }^{\circ}$ andar). CEP: 80060-140 - Curitiba - Paraná (Brasil). Telefone: 41 3360-5231. E-mail: jmggandara@ yahoo.com.br
} 


\section{INTRODUÇÃO}

A distribuição da hotelaria de rede no Estado do Paraná (Brasil) se dá de forma seletiva, pois há uma concentração na sua capital e em algumas cidades do interior, onde o segmento turístico de negócios e o de lazer, com menos expressividade, está atraindo as redes de hotéis (paranaenses, nacionais e internacionais) para esses destinos.

Discutir a hotelaria de rede se torna um desafio, pois as fontes para obter dados são escassas e desatualizadas. Além disso, na ciência geográfica essa temática ainda é incipiente e, portanto a busca pelas questões teóricas e estudos de caso se torna também um gargalo.

Alguns autores ligados à geografia discutiram essa temática. Podem-se citar alguns exemplos, como Bley e Zeglin (2005), que utilizam como objeto de estudo a cidade de Curitiba, buscando compreender a distribuição espacial das redes no espaço urbano, Cruz (2006 e 2007), faz uma leitura da entrada das redes hoteleiras internacionais e sua distribuição dos hotéis a partir da cidade de São Paulo. Silva (2007b) visa compreender as transformações ocorridas na hotelaria de Salvador (Bahia/BA) ao longo dos anos, incluindo uma breve discussão das grandes redes hoteleiras presentes na cidade, Mossato (2007) realiza uma discussão da internacionalização da economia urbana a partir da hotelaria na cidade de Curitiba. Silva (2007a) discute a reorganização espacial da hotelaria de Recife (Pernambuco/PE), enfatizando a concentração de hotéis no Bairro de Boa Viagem durante a década de 1980 e a desvalorização da área central da cidade.

Em Píccolo (2008 e 2011) se faz uma leitura da entrada da rede hoteleira francesa Accor na cidade de Maringá/PR e Rosa (2009) discute a dinâmica da hotelaria e o turismo de negócios e eventos na cidade de Campinas (São Paulo/SP).

Autores de outras áreas abordam a temática seguindo essas perspectivas. Pode-se citar Menezes (2003), que analisa a descentralização dos meios de hospedagem considerando tanto as alterações ocorridas no perfil da demanda quanto considerando aspectos urbanísticos e imobiliários em Curitiba. Spolon (2006) discute o crescimento quantitativo da "indústria hoteleira" da cidade de São Paulo entre 1995 e 2005. Menicucci (2007) aponta as características da hotelaria econômica e as estratégias 
adotadas pela rede Accor na redução da rotatividade em Belo Horizonte e Betim, ambas em Minas Gerais/MG.

Villanueva Ramos (2010) aponta outros estudos (dissertações e teses), como o de Santos (2007) que realizou uma análise histórico espacial do setor hoteleiro no núcleo urbano central de Florianópolis buscando entender as implicações da expansão urbana e turística da cidade sobre a evolução do setor hoteleiro situado em seu núcleo central. Teles (2009) realiza análise sobre o turismo urbano na cidade de São Paulo, onde verifica a proximidade da hotelaria com os atrativos turísticos e com algumas áreas específicas da cidade.

Além das grandes capitais e centros turísticos de lazer há hotéis de redes, nacionais e internacionais, em cidades do interior, que estão passando por um crescimento econômico considerável, devido ao crescimento das atividades relacionadas às indústrias e agroindústrias.

A principal contribuição do presente artigo é discutir sobre a presença da hotelaria de rede em cidades do interior do Estado do Paraná, buscando compreender as motivações e as estratégias de localização desses grupos no território paranaense.

A abordagem desse estudo tem uma perspectiva regional, o que difere de outras pesquisas realizadas, que utilizam uma escala local utilizando, principalmente, como recorte espacial, capitais, como, por exemplo, São Paulo, Florianópolis e Curitiba.

Os meios de hospedagens surgiram ainda no período da Antiguidade e foram sofrendo mudanças ao longo da história. Em meados do século XX, sobretudo a partir do final da Segunda Guerra Mundial, houve um grande avanço e melhoria dos meios de comunicação e de transportes, principalmente o aéreo, além de um crescimento da economia mundial e o advento do turismo (ANDRADE; BRITO; JORGE, 2005). Tais condições proporcionaram uma grande expansão da atividade hoteleira.

Neste contexto as primeiras redes de hotéis surgiram nos Estados Unidos, como, por exemplo, Holiday Inn, Hilton e Quality Courts Motels e Novotel (posteriormente incorporada à rede Accor), Sol Meliá, e Mediterranée, entre outros na Europa (PROSERPIO, 2007).

A partir da década de 1970 redes internacionais começaram a atuar no Brasil, concentrando-se nas grandes capitais, ou seja, São Paulo e Rio de Janeiro e nos destinos turísticos de "sol e praia" (PÍCCOLO, 2008). 
Tais redes ocasionaram uma reestruturação dos hotéis de grupos nacionais para competirem com os hotéis internacionais. Houve um período de recesso econômico nos anos 1980, fato que afetou diversos setores da economia, incluindo a hotelaria (PROSERPIO, 2007).

Na década de 1990, durante o chamado "novo cenário" econômico e com a entrada de novos agentes no setor turístico, observa-se uma entrada expressiva das redes internacionais, culminando em uma competitividade maior principalmente com redes de hotéis nacionais (MOSSATO, 2007).

Neste contexto, as redes, nacionais e internacionais, passaram por uma dispersão pelo território brasileiro, expandindo-se para regiões e cidades onde, até então, os grupos não atuavam, principalmente em cidades que apresentam um dinamismo e crescimento econômico considerável (PÍCCOLO, 2011).

É a partir desse período que houve uma maior representatividade do que se pode chamar de interiorização das redes hoteleiras. A dispersão se dá pelo surgimento de "novos territórios turísticos" de diversas modalidades, como, por exemplo, de negócios, de saúde e turismo religioso.

Esse movimento pelo território é marcado por estratégias de localização dos grupos hoteleiros, através de estudos de demanda e oferta, segmento de mercado e viabilidade econômico-financeira (ANDRADE; BRITO; JORGE, 2005).

O objetivo deste artigo é de analisar a distribuição espacial das redes de hotéis que atuam no Paraná.

Observou-se que no Paraná as redes hoteleiras, de capital nacional e internacional estão distribuídas em onze municípios: Curitiba, Campo Largo, Cascavel, Foz do Iguaçu, Guaíra, Jaguariaíva, Londrina, Maringá, Ponta Grossa, São José dos Pinhais e União da Vitória (Figura 1). 


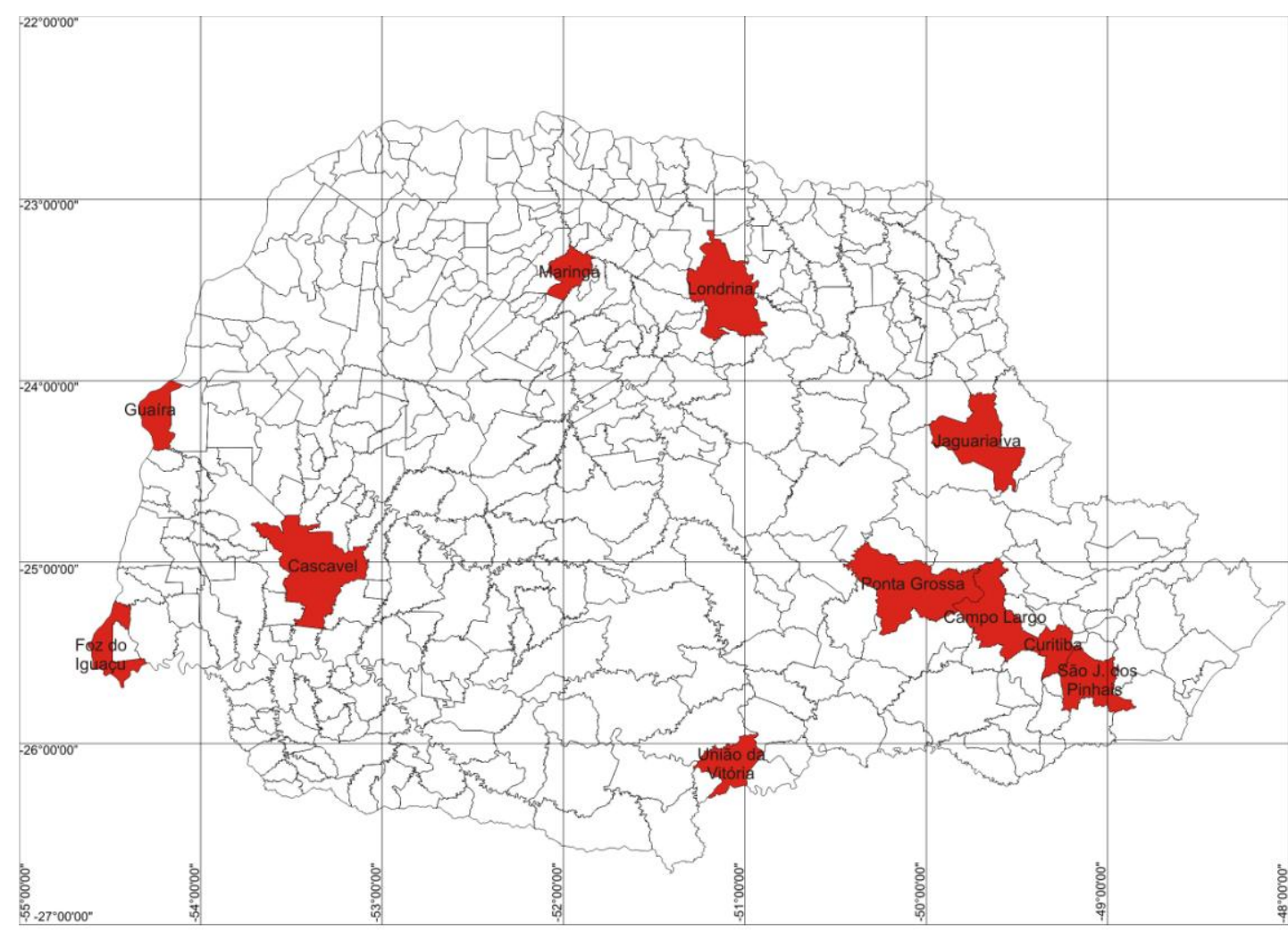

Municípios com presença de hotelaria de rede

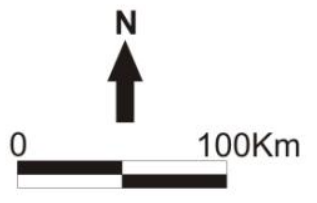

Base:Malhas Municipais - IBGE, 2007.

Fonte: Guia Quatro Rodas, 2010.

Elaboração:Gomes M. F.;Piccolo,D. R., 2010.

FIGURA 1 - PARANÁ: LOCALIZAÇÃO DOS MUNICÍPIOS QUE POSSUEM HOTÉIS DE REDE

No estado há 17 redes de hotéis (Tabela 1).

TABELA 1 - PARANÁ - REDES DE HOTÉIS QUE ATUAM NO ESTADO

\begin{tabular}{|c|c|c|}
\hline Paranaenses & Nacionais & Internacionais \\
\hline $\begin{array}{l}\text { Bourbon Hotéis \& Resorts; } \\
\text { Bristol Hotéis \& Resorts; Elo; } \\
\text { Harbor; Hotéis Deville; Hotéis }\end{array}$ & $\begin{array}{lr}\text { Atlântica Hotels; Blue } \text { Tree } \\
\text { Hotels; } & \text { HDEZ } \\
\text { Empreendimentos; } & \text { Transamérica }\end{array}$ & $\begin{array}{l}\text { Accor; Golden Tulip Hotels, } \\
\text { Inns \& Resorts; Howard } \\
\text { Johnson; InterContinental Hotels }\end{array}$ \\
\hline $\begin{array}{l}\text { Slaviero; Mabu Hotéis \& } \\
\text { Resorts; San Juan Hotéis. }\end{array}$ & Hotéis. & Group; Pestana. \\
\hline
\end{tabular}

Resorts; San Juan Hotéis.

FONTE: GUIA 4 RODAS, 2010.

ORG.: PÍCCOLO, D. R., 2010.

O presente estudo é quantitativo, porém o objetivo não é de criar modelos matemáticos da localização da hotelaria de rede, mas sim de fazer uma análise da distribuição dos hotéis no Estado do Paraná. 
A metodologia utilizada foi uma revisão bibliográfica e leituras pertinentes à temática, procurando destacar as discussões acerca da hotelaria de rede, enfatizando a sua formação, formas de gestão e expansão pelo território e considerações sobre a atividade do turismo e sua segmentação e o contexto da atividade no Estado do Paraná.

A fonte para o levantamento dos hotéis distribuídos pelo Estado foi o Guia 4 Rodas (2010), da Editora Abril, que apresenta uma atualização anual, desde $1966^{1}$ de dados referentes ao turismo e os seus equipamentos, neste caso, os hotéis. A fonte citada possui uma publicação nacional e tem seus dados dentro de uma perspectiva do turista, sendo amplamente utilizada pelos mesmos e agências de viagens, principalmente por sua forma de classificação e, mesmo não sendo oficial, a publicação é bem aceita e respeitada.

Optou-se por esta fonte, pois há uma escassez de informações em órgãos oficiais, como, por exemplo, na Associação Brasileira da Indústria de Hotéis (ABIH) e, também em órgãos do Estado e dos municípios referentes aos hotéis distribuídos nas cidades do Paraná.

Após esse levantamento foi possível verificar quais são e onde estão localizadas as redes hoteleiras no território paranaense.

Através do banco de dados da Secretaria de Turismo do Estado do Paraná (PARANÁ, 2008a), foi possível analisar dados secundários e compreender a realidade do turismo e dos municípios do recorte espacial. A sistematização dos dados resultou na elaboração de tabelas e cartogramas, explorados ao longo de toda a discussão.

\section{FORMAÇÃO E EXPANSÃO DA HOTELARIA DE REDE}

Os meios de hospedagem são equipamentos turísticos fundamentais para o funcionamento da atividade em questão, ou seja, o turismo. Os hotéis estão inseridos em um subsistema, dentro do sistema turístico ${ }^{2}$, denominado "subsistema empresarial ${ }^{33}$ ",

\footnotetext{
${ }^{1}$ Exceto no ano de 1969.

${ }^{2} \mathrm{O}$ sistema turístico é formado por todos os agentes e atividades, que se relacionam ao redor do turismo e assim atender as necessidades dos turistas (BOULLÓN, 2002).
} 
onde estão todas as atividades diretamente ligadas ao turismo, ou seja, fundamentais para a atividade.

É desde o período da Antiguidade que os meios de hospedagem existem. Surgiram com as rotas comerciais, pois estas geraram núcleos urbanos e, consequentemente, os meios de hospedagem, é que atendiam os viajantes que utilizavam as rotas. Ao longo dos anos, estes meios passaram por modificações.

No Brasil os hotéis começaram suas atividades na cidade do Rio de Janeiro, quando a Família Real portuguesa passou a residir na então capital nacional, havendo, assim um crescimento de viajantes que passavam pela cidade (ANDRADE; BRITO; JORGE, 2005).

Com o tempo os meios de hospedagem foram se aprimorando para atender de uma melhor forma o número crescente de viajantes.

Na segunda década do século XX, grande número de hotéis foi construído nos Estados Unidos e Europa, gerado pela prosperidade econômica da época, denotando uma íntima ligação entre hotelaria e desenvolvimento econômico. Consequientemente, dinamismo comercial e intercâmbio de produtos, serviços e pessoas. (SILVA, 2007a, p. 35).

Com o término da Segunda Guerra Mundial houve um grande avanço da hotelaria, pois as melhores condições econômicas e de disponibilidade de tempo aumentaram o fluxo de viagens no mundo.

\footnotetext{
Neste período, o turismo passa a ser uma atividade econômica significativa, principalmente para os países desenvolvidos, nos quais havia crescimento e ampliação da renda da população, o que gerava mais disponibilidades de tempo e recursos para o lazer. O processo de desenvolvimento e de globalização da economia mundial, além de gerar um progressivo fluxo de viagens regionais e internacionais, ampliou de forma acelerada o setor de lazer e de turismo, que passou a ser, efetivamente, o grande promotor das redes hoteleiras. (ANDRADE; BRITO; JORGE, 2005, p. 18).
}

As redes de hotéis formaram-se dentro deste contexto na Europa e nos Estados Unidos, como, por exemplo, a Novotel, Sol Meliá, Hotasa, Holiday Inn, Hilton e Best Western (PROSERPIO, 2007).

\footnotetext{
${ }^{3}$ Além dos alojamentos, há outros elementos, como, transportes, restaurantes, locadoras de veículos, entre outros, além de serviços especializados, como, por exemplo, guias turísticos.
} 
Cabe ressaltar que uma rede de hotéis é formada por três ou mais estabelecimentos. García Almeida (2004, p. 34) aponta que:

[...] una cadena hotelera es un grupo de establecimientos hoteleros que están bajo la misma dirección, tienen objetivos similares y participan en procesos productivos y de prestación de servicios comunes, abarcando múltiples posibilidades de vinculación.

O movimento dado no território pelas redes se dá de forma seletiva, atendendo os principais destinos turísticos de lazer e de negócios do mundo, onde há um fluxo permanente de turistas. A distribuição das redes de hotéis obedece à lógica da seletividade espacial.

Para Gray e Liguori (1998), em análise sobre um estudo de viabilidade do estabelecimento hoteleiro afirmam que são várias as considerações que devem ser feitas sobre a seleção da localização do empreendimento, como por exemplo: o ambiente econômico local, regional ou zoneamento, altura limite de edifícios, facilidade de estacionamento, instalações públicas, a facilidade de tráfego e de acessibilidade, os fatores geográficos, os recursos naturais e o tamanho do terreno.

Pan (2002) categorizou diversos fatores para a seleção da localização de um determinado hotel turístico, baseados na adequação do empreendimento, como: conveniência e tráfego, boa percepção visual, instalações públicas e outros serviços, a aplicação de certas regulamentações, e flexibilidade do espaço.

Através de estudo de demanda e oferta, segmento de mercado e viabilidade econômico-financeira é que este movimento seletivo ocorre no território, ou seja, através de estratégias de localização dos grupos hoteleiros (ANDRADE; BRITO; JORGE, 2005).

Para Matorell Cuniil (2002, p. 64): “con el crecimiento de los viajes y del comercio internacional, una táctica empleada por las cadenas hoteleras es seguir a sus clientes a los destinos internacionales".

No mercado brasileiro as redes internacionais começaram a operar a partir da década de 1970 nas cidades de São Paulo (SP) e Rio de Janeiro (Rio de Janeiro/RJ), além de algumas cidades turísticas de "sol e praia" e destinos de negócios, como, por exemplo, São José dos Campos, no interior paulista (PÍCCOLO, 2008). 
O crescimento da hotelaria no Brasil, na década de 1970, estava relacionado ao crescimento do número de viagens, estimulada pelo desenvolvimento dos transportes aéreo e rodoviário daquele período (ROSA, 2009).

O primeiro hotel de rede internacional foi inaugurado em 1971, o Hilton em São Paulo (CWIKLA, 2001) e (PROSERPIO, 2007), voltado para o público executivo. Em meados da década de 1970 começaram a operar no Brasil outras redes, entre elas: Holiday Inn (Campinas/SP), Sheraton (Rio de Janeiro/RJ) e Intercontinental (Rio de Janeiro/RJ) , conforme ressaltam Gorini e Mendes (2005). Ainda mencionam que em 1975, foram inaugurados o Le Méridien (Rio de Janeiro/RJ) e o Club Med (Itaparica/BA), em 1977, o Novotel (São Paulo e São José dos Campos/SP).

Andrade, Brito e Jorge (2005, p. 22) afirmam que "mesmo sem um número importante de hotéis, essas redes vão criar uma nova orientação na oferta hoteleira, com novos padrões de serviços e de preços".

A entrada das redes de hotéis internacionais no Brasil ocasionou efeitos imediatos no parque hoteleiro de bandeira nacional e nos hotéis independentes, como a reestruturação, pois os hotéis internacionais ocasionaram o aumento da concorrência, elevaram a qualidade dos serviços prestados e profissionalizaram a gestão (PROSERPIO, 2007).

A constante internacionalização do mercado hoteleiro brasileiro e o aumento da concorrência ocasionada pela entrada das redes internacionais levaram a hotelaria nacional a mudar suas características, se adequando as novas exigências do mercado (MENICUCCI, 2007).

Alguns hotéis de capital local e redes nacionais, muitas vezes não conseguem competir com os grandes grupos hoteleiros de capital internacional.

\footnotetext{
A competitividade dos hotéis locais com a hotelaria organizada em redes esbarra ainda nos valores praticados. A maioria dos hotéis locais não consegue oferecer um padrão de qualidade semelhante ao dos hotéis internacionais, por exemplo, pelo preço praticado por eles. Estabelece-se, então, uma situação conflituosa, pois se os hotéis locais oferecem preços semelhantes, não conseguem manter o padrão de qualidade, por outro lado, se primam pela qualidade, não conseguem oferecer preços competitivos. (MOSSATO, 2007, p. 102).
}

As redes hoteleiras fazem parte de um setor altamente competitivo, do qual há os hotéis locais e de pequeno, médio e até grande porte. Há uma grande vantagem das 
redes em relação aos estabelecimentos locais no que diz respeito à tecnologia avançada, tornando esta competitividade mais desleal (HOKAIDEN-DA-SILVA; TEIXEIRA, 2009).

O setor hoteleiro no Brasil sofreu um recuo em meados dos anos de 1980. Pereira e Lucena 2009 (p. 57) afirmam que:

No final da década de 70 e no início da de 80, o ambiente de negócios no Brasil era favorável ao desenvolvimento do setor hoteleiro. Diferentemente do que ocorreu ao longo da década de 80 , momento que não havia facilidades de financiar hotéis e nem incentivos governamentais para o setor hoteleiro.

O período da década de 1980 ficou conhecido como "década perdida", pois o Brasil passou por uma crise econômica, atingindo diversos segmentos da economia, inclusive o hoteleiro e, com isso, houve um recesso na entrada das redes internacionais no mercado brasileiro (PÍCCOLO, 2011). Proserpio (2007, p. 72) afirma que "a retração econômica verificada no Brasil na 'década perdida', não poupou o segmento de hospedagem".

Neste primeiro momento, ou seja, década de 1970 e 1980 as redes de hotéis, principalmente as internacionais, concentraram-se nas principais capitais, destinos turísticos de negócios e de lazer do país (PÍCCOLO, 2011)

Com o "novo cenário"4 econômico, ou seja, com a abertura econômica e com a implantação do Plano Real na década de 1990, além da entrada de novos agentes na atividade turística, como o poder público, incorporadoras imobiliárias, fundos institucionais, entre outros, é que houve uma intensificação da dispersão das redes pelo território e uma maior representatividade da entrada de grupos hoteleiros de capital internacional.

Para Santos e Silveira (2008, p. 235) houve, neste período, um crescimento do número de estabelecimentos hoteleiros no país, principalmente em São Paulo, Rio de Janeiro e Brasília (Distrito Federal/DF), fato vinculado ao dinamismo da indústria, comércio e serviços e as funções do governo.

Além da estabilização econômica houve a entrada de novos agentes no setor, como os fundos de pensão, construtoras, incorporadoras imobiliárias, investidores e linhas especiais de financiamento para os grandes complexos hoteleiros (RIBEIRO,

\footnotetext{
${ }^{4}$ Esse período corresponde ao da abertura econômica e a implantação do Plano Real na década de 1990.
} 
2005), além do poder público, principalmente investimentos em infraestruturas turísticas, através do PRODETUR/NE (Programa de Desenvolvimento do Nordeste) e do BNDES (Banco Nacional de Desenvolvimento Econômico e Social), que a partir da década de 1990 passou a repassar recursos para o setor hoteleiro e ao setor do turismo estimulando a entrada de novas redes internacionais (PROSERPIO, 2007).

Os fundos de pensão do Banco do Brasil (Previ), da Caixa Econômica Federal (Funcef) e da Petrobrás (Petros) passaram a investir no mercado hoteleiro brasileiro. Fonte? Dessa forma, em 1996 foi inaugurado em São Paulo o Hotel Sol Meliá, com 300 quartos e investimento de $\mathrm{R} \$ 84$ milhões, uma parceria entre 35 fundos institucionais (PROSERPIO, 2007).

Posteriormente, os fundos adquiriram os imóveis ou financiaram as construções dos hotéis Transamérica Morro do Conselho, em Salvador/BA, do Meliá Maceió (Alagoas/AL), dos hotéis das redes Marriott, Accor e Superclub Breezers no complexo Costa do Sauípe (BA), do Le Méridien Rio, do Renaissance São Paulo (rede Marriott) e do resort Cabo de Santo Agostinho, em Pernambuco, além de várias novas unidades da rede Accor, conforme apontam Proserpio (2007) e Gorini e Mendes (2005).

Nesta nova dinâmica da hotelaria de rede no Brasil os hotéis começaram a se dispersarem pelo território, operando em diferentes capitais e, também, em cidades do interior.

O contexto da dispersão dos hotéis para o interior ocorre com a dinâmica de outras redes que oferecem diferentes serviços, pois se observa que "há uma tendência à expansão territorial dos grandes capitais comerciais pelo interior, reforçando o papel das cidades médias como pontos de consumo importantes". (SPOSITO, 2004, p. 355).

Frente a este processo, pode-se observar uma dispersão dos hotéis de redes para capitais como, por exemplo, Belo Horizonte/MG, Porto Alegre (Rio Grande do Sul/RS) e Curitiba/PR e, também, para cidades do interior, como, Maringá/PR, São José do Rio Preto/SP, Uberlândia/MG, entre outras, sobretudo na década de 1990 e nos anos 2000, com maior expressividade (PÍCCOLO, 2011).

Almeida (2010) aponta que no interior do Estado do Rio de Janeiro observa-se a expansão das redes de hotéis, principalmente em cidades, como, por exemplo, Macaé, Cabo Frio e Campos dos Goytacazes. 
Neste período ocorre o que se pode denominar de interiorização da hoteleira de rede no país, pois com o desenvolvimento econômico de cidades do interior, as redes de hotéis nacionais e internacionais, começaram a operar em tais localidades.

Os principais clientes das redes hoteleiras são os homens de negócios, que viajam por várias partes do mundo com a finalidade de realizarem suas atividades. Este tipo de turista se torna mais exigente, pois conhece a qualidade dos serviços prestados por um hotel de rede em nível mundial (PÍCCOLO, 2008).

Cabe apontar que a partir do século XX a atividade turística vem passando por uma segmentação. Estas modalidades são apontadas como segmentos mercadológicos, onde a atividade turística se organiza.

As novas modalidades do turismo surgiram para atender de maneira mais satisfatória as necessidades dos turistas. A segmentação do turismo atende as necessidades mais específicas de cada pessoa, o que não acontece no turismo de massa, onde pacotes são vendidos para grupos muito heterogêneos, não atendendo assim os gostos e necessidades mais específicas de todos os turistas, ou seja, de cada pessoa (MORAES, 1999).

O turismo de negócios é uma modalidade turística bastante representativa e importante, pois não gera sazonalidade nos destinos onde está presente.

Wada (2009, p. 215) aponta que:

Turismo de negócios é o conjunto de atividades que resultam em viagens sob a responsabilidade de uma pessoa jurídica - empresa, órgão público, entidade de classe ou ONG - que absorve todas as despesas previstas em sua política de viagem e se preocupa com outros aspectos como segurança, saúde e bemestar do viajante, com intenção de garantir sua produtividade enquanto esteja fora de seu local habitual de trabalho.

No Paraná observa-se que a modalidade do turismo de negócios vem crescendo nos últimos anos, em diferentes cidades, atraindo redes hoteleiras para tais destinos com a finalidade de atender os homens de negócios, conforme será abordado a seguir.

\section{CARACTERIZAÇÃO DA DEMANDA TURÍSTICA NO PARANÁ}

Os principais núcleos receptores turísticos do Paraná são as cidades de Curitiba, Foz do Iguaçu, Londrina, Maringá e Cascavel, onde há uma demanda de turistas mais efetiva, de diferentes modalidades. 
Na capital, Curitiba, o segmento de negócios se destacou como principal motivo de viagem nos últimos 5 anos a partir de 2001 (Tabela 2).

TABELA 2 - CURITIBA - MOTIVO DA VIAGEM DOS TURISTAS (2000, 2001, 2002, 2003, 2004, 2005 e 2006)

\begin{tabular}{c|c|c|c|c|c|c|c}
\hline Motivo da Viagem & $\mathbf{2 0 0 0} \%$ & $\mathbf{2 0 0 1} \%$ & $\mathbf{2 0 0 2} \%$ & $\mathbf{2 0 0 3} \%$ & $\mathbf{2 0 0 4} \%$ & $\mathbf{2 0 0 5} \%$ & $\mathbf{2 0 0 6} \%$ \\
\hline Compras & 0,9 & - & 0,2 & 0,5 & 0,5 & 0,5 & 0,7 \\
\hline Eventos & 6,7 & 12,3 & 9,3 & 9,9 & 9,0 & 6,6 & 8,1 \\
\hline Negócios & 32,7 & 44,5 & 38,2 & 38,5 & 35,4 & 33,9 & 34,2 \\
\hline Parentes/Amigos & 36,8 & 22,2 & 25,1 & 23,0 & 28,4 & 30,3 & 30,0 \\
\hline Tratamento de Saúde & 6,2 & 9,8 & 5,3 & 7,2 & 7,3 & 6,3 & 6,5 \\
\hline Lazer & 16,7 & 9,2 & 21,3 & 16,6 & 15,9 & 19,3 & 18,4 \\
\hline Outros & - & 2,0 & 0,6 & 4,3 & 3,5 & 3,1 & 2,1 \\
\hline Total & 100,0 & 100,0 & 100,0 & 100,0 & 100,0 & 100,0 & 100,0 \\
\hline
\end{tabular}

FONTE: PARANÁ, 2007.

ORG.: PÍCCOLO, D. R., 2010.

Observa-se que o segmento de negócios é a principal motivação das viagens para a capital paranaense, sendo que sua média foi de 38,5\% no ano de 2003, considerando os turistas oriundos de estados brasileiros. O lazer teve média de $16,0 \%$ e os eventos 10,0\%. Além da aptidão aos negócios, por ser um centro urbano industrializado, Curitiba atrai turistas que buscam o lazer.

No interior do Estado o segmento de negócios também é bastante expressivo. Em Cascavel, localizada no oeste do Paraná, o principal motivo de viagem dos turistas é, também, o de negócios (Tabela 3).

TABELA 3 - CASCAVEL - MOTIVO DA VIAGEM DOS TURISTAS (2005, 2006 e 2007).

\begin{tabular}{c|c|c|c}
\hline Motivo da Viagem & $\mathbf{2 0 0 5} \%$ & $\mathbf{2 0 0 6} \%$ & $\mathbf{2 0 0 7} \%$ \\
\hline Negócios & 46,5 & 54,5 & 48,7 \\
\hline Parentes/Amigos & 34,8 & 32,0 & 26,5 \\
\hline Compras & --- & 1,0 & 0,6 \\
\hline Tratamento de Saúde & 3,3 & 4,5 & 3,7 \\
\hline Eventos & 7,3 & 1,8 & 4,3 \\
\hline Lazer & 5,3 & 3,9 & 11,7 \\
\hline Outros & 2,8 & 2,3 & 4,5 \\
\hline Total & 100,0 & 100,0 & 100,0
\end{tabular}

FONTE: PARANÁ, 2008b.

ORG.: PÍCCOLO, D. R., 2010

$\mathrm{Na}$ cidade de Cascavel a modalidade de negócios é a mais expressiva, sendo que em 2006 chegou a representar 54,4\% do motivo da viagem de turistas a cidade. O motivo "eventos" apresentou uma queda de 7,3\% em 2005 para 4,3\% em 2007. Houve um crescimento significativo no segmento de lazer, chegando a 11,7\% em 2007. 
Em Londrina, segunda maior cidade do Estado, localizada em sua porção norte, negócios foi o motivo que mais atraiu turistas para a cidade em 2007 (Tabela 4).

TABELA 4 - LONDRINA - MOTIVO DA VIAGEM DOS TURISTAS (2005, 2006 E 2007)

\begin{tabular}{c|c|c|c}
\hline Motivo da Viagem & $\mathbf{2 0 0 5} \%$ & $\mathbf{2 0 0 6} \%$ & $\mathbf{2 0 0 7} \%$ \\
\hline Negócios & 43,2 & 47,9 & 44,2 \\
\hline Parentes/Amigos & 30,3 & 30,1 & 23,5 \\
\hline Compras & 0,7 & 0,2 & 0,6 \\
\hline Tratamento de Saúde & 3,3 & 3,6 & 3,4 \\
\hline Eventos & 12,4 & 3,8 & 4,8 \\
\hline Lazer & 8,9 & 5,4 & 11,5 \\
\hline Outros & 1,2 & 9,0 & 12,0 \\
\hline Total & 100,0 & 100,0 & 100,0 \\
\hline
\end{tabular}

FONTE: PARANÁ, 2008d.

ORG.: PÍCCOLO, D. R., 2010.

Em Londrina, o segmento de negócios é o mais expressivo, representando, em 2006, 47,9\% dos motivos das viagens de turistas a cidade. A modalidade de eventos apresentou uma queda significativa, de 12,4\% em 2005 para 4,8\% em 2007. O segmento de lazer apresentou um crescimento significativo, comparando os anos de 2005 e 2007.

Maringá, localizada no noroeste paranaense, tem atraído turistas de negócios pelo seu desenvolvimento e crescimento econômico (Tabela 5).

TABELA 5 - MARINGÁ - MOTIVO DA VIAGEM DOS TURISTAS (2005, 2006 E 2007)

\begin{tabular}{c|c|c|c}
\hline Motivo da Viagem & $\mathbf{2 0 0 5} \%$ & $\mathbf{2 0 0 6} \%$ & $\mathbf{2 0 0 7} \%$ \\
\hline Negócios & 51,2 & 45,1 & 50,3 \\
\hline Parentes/Amigos & 29,3 & 31,8 & 26,3 \\
\hline Compras & 2,0 & 2,8 & 1,3 \\
\hline Tratamento de Saúde & 3,2 & 4,7 & 3,9 \\
\hline Eventos & 6,9 & 3,7 & 2,2 \\
\hline Lazer & 5,6 & 6,0 & 8,7 \\
\hline Outros & 1,8 & 5,9 & 7,3 \\
\hline Total & 100,0 & 100,0 & 100,0 \\
\hline
\end{tabular}

FONTE: PARANÁ, 2008e.

ORG.: PÍCCOLO, D. R., 2010.

Na cidade de Maringá o segmento de negócios é o mais expressivo, chegando a 50,3\% em 2007 do motivo das viagens dos turistas à cidade. As modalidades de eventos e compras apresentaram uma queda na representatividade dos motivos de viagens.

A cidade de Foz do Iguaçu, localizada a oeste do Estado possui um potencial turístico muito grande, e por isso o cenário é diferente dos demais apresentados (Tabela $6)$. 
TABELA 6 - FOZ DO IGUAÇU - MOTIVO DA VIAGEM DOS TURISTAS (2005, 2006 E 2007).

\begin{tabular}{c|c|c|c}
\hline Motivo da Viagem & $\mathbf{2 0 0 5} \%$ & $\mathbf{2 0 0 6} \%$ & $\mathbf{2 0 0 7} \%$ \\
\hline Compras & 4,8 & 5,3 & 4,8 \\
\hline Eventos & 1,4 & 4,2 & 3,1 \\
\hline Negócios & 15,7 & 22,6 & 23,0 \\
\hline Parentes/Amigos & 20,3 & 15,0 & 15,1 \\
\hline Lazer & 55,0 & 52,0 & 52,2 \\
\hline Outros & 2,8 & 0,9 & 1,8 \\
\hline Total & 100,0 & 100,0 & 100,0 \\
\hline
\end{tabular}

FONTE: PARANÁ, 2008a.

ORG.: PÍCCOLO, D. R., 2010.

Em Foz do Iguaçu a modalidade turística mais representativa é a de lazer, apresentando um crescimento de 55,0\% em 2005 para 52,2\% em 2007. Verifica-se que o segmento de negócios passou por um crescimento entre os anos de 2005 e 2007. Houve queda entre 2006 e 2007 na modalidade de eventos. O principal atrativo turístico da cidade são as Cataratas do Iguaçu, que recebe turistas do Brasil e de outros países do mundo.

Cabe ressaltar que nas cidades de Londrina, Cascavel, Foz do Iguaçu e Maringá muitos turistas visitam tais localidades para visitar "Parentes/Amigos".

O litoral paranaense ${ }^{5}$, nas temporadas, recebe cerca de um milhão de turistas, que procuram esse destino para o lazer. Segundo dados da Setu (2008c) os visitantes do litoral buscam lazer quando viajam para essa região (Tabela 7).

TABELA 7 - LITORAL DO PARANÁ - MOTIVO DA VIAGEM DOS TURISTAS (2006)

\begin{tabular}{c|c|c|c|c|c|c}
\hline $\begin{array}{c}\text { Motivo das } \\
\text { Viagens \% }\end{array}$ & Lazer & Parentes/Amigos & Negócios & Eventos & Outros & Total \\
\hline Antonina & 49,3 & 23,5 & 9,6 & 17,5 & 0,5 & 100,0 \\
\hline Guaraqueçaba & 70,8 & 14,6 & 2,1 & 10,4 & 2,1 & 100,0 \\
\hline Guaratuba & 83,7 & 6,2 & 8,6 & 0,9 & 0,6 & 100,0 \\
\hline Ilha do Mel & 93,7 & 1,4 & 4,4 & - & 0,5 & 100,0 \\
\hline Matinhos & 87,8 & 5,3 & 6,0 & 0,2 & 0,7 & 100,0 \\
\hline Morretes & 52,1 & 32,6 & 13,6 & 1,3 & 0,4 & 100,0 \\
\hline Paranaguá & 41,5 & 25,4 & 31,9 & - & 1,2 & 100,0 \\
\hline Pontal do Paraná & 80,0 & 9,9 & 15,1 & 0,5 & 1,4 & 100,0 \\
\hline Total & 77,7 & 10,6 & 9,4 & 1,4 & 0,9 & 100,0 \\
\hline
\end{tabular}

FONTE: PARANÁ, 2008c.

ORG.: PÍCCOLO, D. R., 2010.

\footnotetext{
5 O litoral paranaense é composto por 7 municípios: Antonina, Guaraqueçaba, Guaratuba, Matinhos, Morretes, Paranaguá e Pontal do Paraná.
} 
No litoral a modalidade de lazer é a mais significativa no motivo dos turistas que procuram essa região do Estado, representando 77,7\% do total em 2008. O segmento de negócios representou 9,4\% das motivações das viagens ao litoral, diferentemente das outras cidades do recorte espacial da presente discussão.

O crescimento do turismo de negócios e o de lazer nas cidades do Paraná vem balizando a distribuição de redes de hotéis nos municípios do recorte espacial.

\section{DISTRIBUIÇÃO ESPACIAL DA HOTELARIA DE REDE NO PARANÁ}

As redes de hotéis estão, cada vez mais, se concentrando nos principais centros de negócios, ou seja, na capital e em cidades do interior, como, por exemplo, Maringá, Londrina e Cascavel, com demanda turística permanente e na cidade turística de Foz do Iguaçu, que recebe uma demanda voltada para lazer e eventos.

No Estado 88,5\% dos meios de hospedagem são empresas únicas e 10,6\% são constituídos pelas redes, que se concentram nas principais cidades do Paraná, como Curitiba, Foz do Iguaçu, Londrina e Maringá (IPARDES, 2008).

Nestas cidades há um crescimento e dinamismo econômico favorável, que atraem os hotéis de redes, pois há uma presença considerável de homens de negócios que as procuram, principais clientes das redes.

Em Curitiba, São José dos Pinhais, Foz do Iguaçu e Maringá há presença de hotéis de redes internacionais. Nas demais cidades são redes de capital nacional que nelas atuam (Tabela 8).

As redes de hotéis de capital internacional estão localizadas em Curitiba e nas cidades de sua região metropolitana (Campo Largo e São José dos Pinhais) e no interior, nas cidades de Maringá e Foz do Iguaçu.

TABELA 8 - PARANÁ - QUANTIDADE DE REDE DE HOTÉIS POR CIDADE NO ESTADO

\begin{tabular}{c|l|l|c}
\hline Cidades & \multicolumn{1}{|c|}{ Redes Internacionais } & \multicolumn{1}{c}{ Total } \\
\hline Campo Largo & $\begin{array}{l}\text { Golden Tulip Hotels, Inns } \\
\text { \& Resorts. }\end{array}$ & \multicolumn{1}{|c}{01} \\
\hline Cascavel & & $\begin{array}{l}\text { Bourbon Hotéis \& } \\
\text { Resorts; Hotéis Deville; } \\
\text { Harbor. }\end{array}$ & 03 \\
\hline
\end{tabular}

Continua... 
Continuação...

\begin{tabular}{|c|c|c|c|}
\hline Curitiba & $\begin{array}{lr}\text { Accor; Golden } & \text { Tulip } \\
\text { Hotels, Inns \& } & \text { Resorts; } \\
\text { InterContinental } & \text { Hotels } \\
\text { Group; Pestana. } & \end{array}$ & $\begin{array}{l}\text { Atlântica Hotels; } \\
\text { Bourbon Hotéis \& } \\
\text { Resorts; Blue Tree } \\
\text { Hotels; Bristol Hotéis \& } \\
\text { Resorts; Harbor; HDEZ } \\
\text { Empreendimentos; } \\
\text { Hotéis Deville; Elo; } \\
\text { Hotéis Slaviero; Mabu } \\
\text { Hotéis e Resorts; } \\
\text { Transamerica Hotéis; } \\
\text { San Juan Hotéis. }\end{array}$ & 16 \\
\hline Foz do Iguaçu & $\begin{array}{l}\text { Golden Tulip Hotels Inns } \\
\text { \& Resorts }\end{array}$ & $\begin{array}{l}\text { Bourbon Hotéis \& } \\
\text { Resorts; Bristol Hotéis \& } \\
\text { Resorts; Harbor; Mabu } \\
\text { Hotéis e Resorts; San } \\
\text { Juan Hotéis. }\end{array}$ & 06 \\
\hline Guaíra & & Hotéis Deville. & 01 \\
\hline Jaguariaíva & & San Juan Hotéis. & 01 \\
\hline Londrina & & $\begin{array}{l}\text { Atlântica Hotels; Blue } \\
\text { Tree Hotels; Bourbon } \\
\text { Hotéis \& Resorts; Bristol } \\
\text { Hotéis \& Resorts; } \\
\text { Harbor. }\end{array}$ & 05 \\
\hline Maringá & Accor. & $\begin{array}{l}\text { Bristol Hotéis \& Resorts; } \\
\text { Hotéis Deville; Elo; } \\
\text { Mabu Hotéis e Resorts. }\end{array}$ & 05 \\
\hline Ponta Grossa & & $\begin{array}{l}\text { Bristol Hotéis \& Resorts; } \\
\text { Hotéis Slaviero. }\end{array}$ & 02 \\
\hline São José dos Pinhais & $\begin{array}{l}\text { Accor; Golden } \text { Tulip } \\
\text { Hotels, Inns \& Resorts; } \\
\text { Howard Johnson. }\end{array}$ & Bristol Hotéis \& Resorts. & 04 \\
\hline União da Vitória & & $\begin{array}{l}\text { HDEZ } \\
\text { Empreendimentos. }\end{array}$ & 01 \\
\hline
\end{tabular}

FONTE: GUIA 4 RODAS, 2010.

ORG.: PÍCCOLO, D. R., 2010.

Na capital do Estado há uma maior concentração de hotéis de rede, sendo 16. Deste total, 4 são de capital internacional e 12 hotéis são de capital nacional. Na cidade de Campo Largo há 1 hotel de rede, que é internacional. Em São José dos Pinhais há 4 redes atuando na cidade, sendo 3 internacionais e 1 nacional. Verifica-se que as redes mais atuantes nesta porção do Estado são a Accor e a Bristol Hotéis \& Resorts.

No interior do Estado, em Foz do Iguaçu há 6 redes (1 internacional e 5 nacionais). De capital internacional há a rede Golden Tulip Hotels Inns \& Resorts e de capital nacional são as redes Bourbon Hotéis \& Resorts, Bristol Hotéis \& Resorts, Harbor, Mabu Hotéis e Resorts e San Juan Hotéis. 
Na cidade de Maringá há 5 redes atuando, sendo 1 internacional (Accor) e 4 nacionais (Bristol Hotéis \& Resorts, Hotéis Deville, Elo e Mabu Hotéis e Resorts).

Em Londrina, segunda maior cidade do Estado, há 5 redes que atuam. Todas são de capital nacional: Atlântica Hotels, Blue Tree Hotels, Bourbon Hotéis \& Resorts, Bristol Hotéis \& Resorts e Harbor.

Há 3 redes de capital nacional atuando na cidade de Cascavel, sendo elas: Bourbon Hotéis \& Resorts; Hotéis Deville; Harbor.

Na cidade de Ponta Grossa são 2 redes, nacionais, que atuam: Bristol Hotéis \& Resorts; Hotéis Slaviero.

Outras cidades do interior, de menor porte, também possuem hotéis de redes. Em Guairá há 1 de rede, a Hotéis Deville, em Jaguariaíva 1 da rede San Juan Hotéis, que são paranaenses e em União da Vitória é a rede HDEZ, nacional, quem atua (Figura 2).

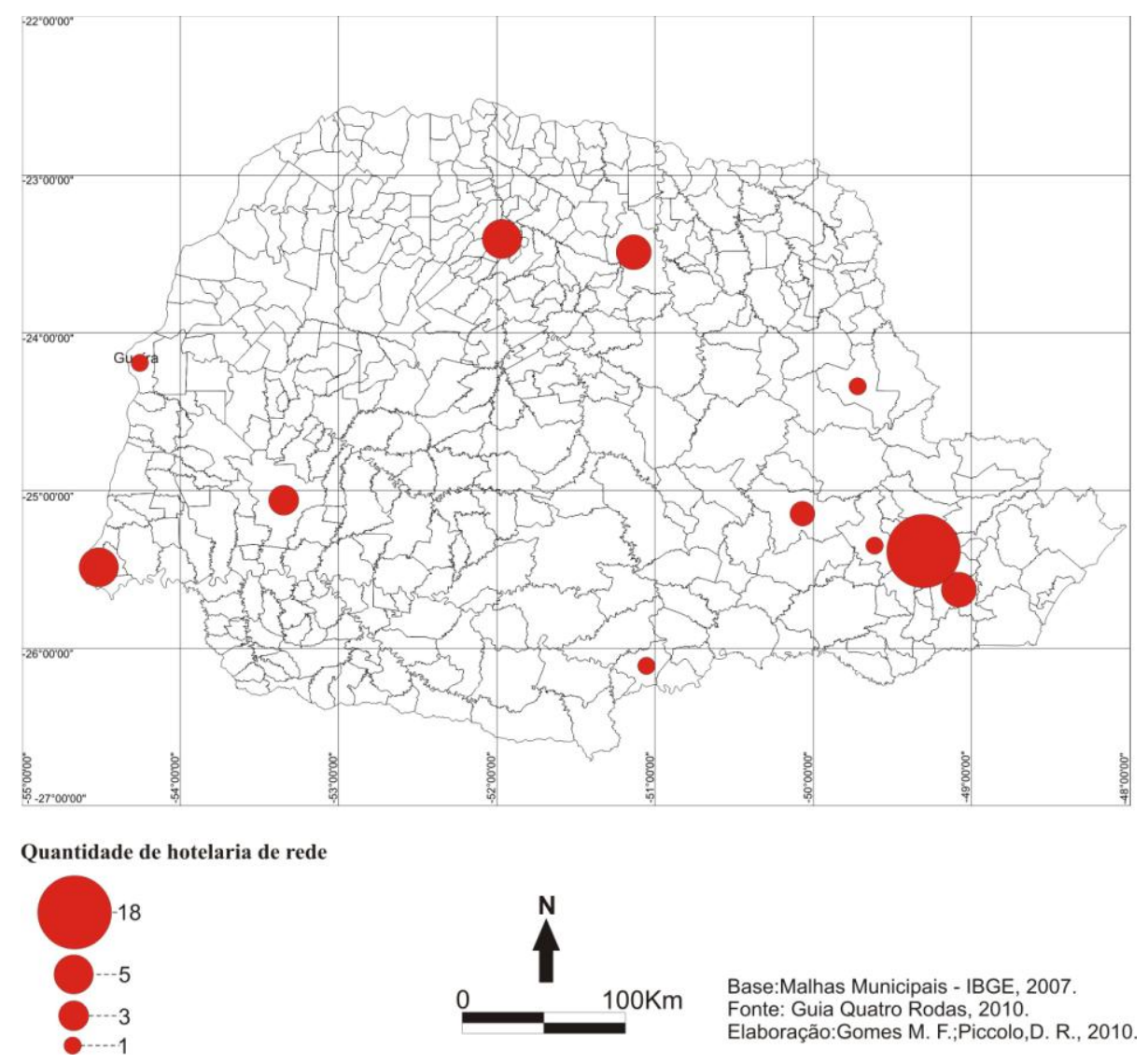

FIGURA 2 - PARANÁ - DISTRIBUIÇÃO ESPACIAL DA QUANTIDADE DE REDES DE HOTÉIS POR MUNICÍPIOS NO ESTADO (2010). 
Em Curitiba e região metropolitana há 21 redes hoteleiras atuando, onde ocorre uma concentração das mesmas. Essa questão se dá pelo segmento turístico de negócios, que atrai os principais clientes das redes. Esta região do Estado possui grandes empresas e indústrias, além de abrigar, no município de São José dos Pinhais, o terceiro pólo automotivo do país.

Nas cidades de Londrina e Maringá o turismo de negócios também é o mais expressivo e, por isso, há uma concentração de redes nesses municípios, totalizando 5, respectivamente. Em Foz do Iguaçu 6 redes atuam, porém o segmento de lazer é o mais expressivo, atraindo uma demanda permanente para este destino que utilizam os hotéis de redes.

Outra questão pertinente e que deve ser apontada é a falta de redes de hotéis no litoral paranaense. Nessa região do Estado, a modalidade de lazer é a mais expressiva e esse fator pode ser bastante relevante para a ausência das redes hoteleiras, pois, no Paraná, tais grupos atuam onde o segmento de negócios é mais relevante, pois este gera uma demanda permanente de turistas, os chamados homens de negócios.

\section{CONSIDERAÇÕES FINAIS}

As redes de hotéis começaram a se formar a partir do fim da Segunda Guerra Mundial, fato proporcionado pelo avanço das comunicações, dos transportes e ao crescimento da atividade turística.

Na década de 1970 as redes hoteleiras internacionais começaram a operar no Brasil. Houve, primeiramente, uma concentração desses grupos nas principais capitais e destinos turísticos de "sol e praia" do país. Nos anos de 1980 houve uma retração econômica e, com isso, a entrada dessas redes no mercado nacional não foi tão expressiva, mas na década de 1990, como o "novo cenário" econômico, observa-se uma maior intensidade da entrada das redes de hotéis internacionais no Brasil.

A partir deste momento as redes nacionais também começam a se expandir e acompanham a dispersão territorial das internacionais, que começam a atuar em outras capitais, destinos turísticos de negócios e de lazer. 
Há o que se pode chamar de interiorização da rede hoteleira no Brasil, pois além das capitais em algumas cidades do interior, sobretudo naquelas onde há um desenvolvimento econômico favorável para o turismo de negócios, as redes de hotéis começaram a operar. Esse processo foi intensificado nos anos 2000.

Cabe ressaltar que mesmo com o processo mencionado acima, no Estado do Paraná há uma grande concentração de hotéis em Curitiba e na Região Metropolitana de Curitiba (RMC). Há, ainda, um número expressivo de hotéis de rede em cidades, como Foz do Iguaçu, Londrina e Maringá.

Essa expansão das redes hoteleiras no Estado, de maneira geral, se dá pelo crescimento econômico das cidades e ao desenvolvimento do turismo de negócios e, também pelo turismo de lazer no caso de Foz do Iguaçu, pois esse fator acaba gerando uma demanda permanente de homens de negócios para esses destinos.

\section{REFERÊNCIAS}

ALMEIDA, G. M. M. Avaliação e classificação da qualidade de meios de hospedagens segundo a percepção dos hóspedes. Dissertação (Mestrado em Engenharia de Produção). Universidade Estadual do Norte Fluminense, Campos dos Goytacazes, 2010.

ANDRADE, N.; BRITO, P. L.; JORGE, W. E. HOTEL: planejamento e projeto. São Paulo: Editora SENAC, 8. ed., 2005.

BLEY, L.; ZEGLIN, S. do R. R. Espaço Urbano: a função hoteleira em Curitiba. Conhecimento Interativo, São José dos Pinhais, PR. V. 1, n. 1, p. 33-55, jul./dez., 2005.

BOUllón, R. C. Planejamento do Espaço Turístico. Tradução: Josely Vianna Baptista. Bauru: EDUSC, 2002.

CWIKLA, L. M. W. Qualidade de atendimento: estudo de multicasos em hotéis de luxo de Foz do Iguaçu. Dissertação (Mestrado em Engenharia de Produção). Universidade Federal de Santa Catarina, 2001.

CRUZ, R. C. A. da. Os paradoxos do turismo na cidade de São Paulo. In: CARLOS, A. F. A; OLIVEIRA, A. U. de. (Orgs.). Geografia das metrópoles. São Paulo: Contexto, p. 201-212, 2006.

2007.

. Geografias do Turismo: de lugares a pseudo-lugares. São Paulo: Roca, 
GARCÍA ALMEIDA, D. J. La transferencia de conocimiento en la expansión de las cadenas hoteleras. Madrid: FINTUR, 2004.

GORINE, A.P.F; MENDES, E. da F. Setor de Turismo no Brasil: segmento de hotelaria. In: BNDES Setorial, Rio de Janeiro, n. 22, p. 111-150, set., 2005.

GUIA 4 RODAS. São Paulo: Editora Abril, 2010.

GRAY, W. S., LIGUORI, S. C. Hotel and Motel Management and Operations. In: Prentice-Hall, Englewood Cliffs. Nova Jersey, 1998.

HOKAIDEN-DA-SILVA, A. J.; TEIXEIRA, R. M. Análise dos relacionamentos interorganizacionais em empresas do setor hoteleiro de Curitiba/PR: estudo comparativo de casos. In: Revista Brasileira de Pesquisa em Turismo, São Paulo, v. 3, n. 2, p. 24 48, ago. 2009.

IPARDES. INSTITUTO PARANAENSE DE DESENVOLVIMENTO ECONÔMICO E SOCIAL. Cadeia Produtiva do Turismo no Paraná: estudo sobre as regiões turísticas do Estado. Curitiba: IPARDES, 2008.

MATORELl CUNILL, O. Cadenas Hoteleras: Analisis Del Top 10. Barcelona: Ed. Ariel, 2002.

MENEZES, V.O. A descentralização dos meios de hospedagens em Curitiba de 1992 - 2001. Dissertação (Mestrado em Administração de Empresas Turísticas). Universidade de Extremadura, Curitiba 2003.

MENICUCCI, C. M. B. F. Rotatividade na hotelaria econômica: uma investigação nos hotéis Ibis de Belo Horizonte e Betim. Dissertação (Mestrado em Turismo e Meio Ambiente). Centro Universitário UNA, Belo Horizonte, 2007.

MORAES, C. C. A. Turismo - Segmentação de Mercado: um estudo introdutório. In: ANSARAH, M. G. R. (Org.). Turismo: segmentação de mercado. São Paulo: Futura, p. 13-33, 1999.

MOSSATO, D. E. C. A internacionalização da economia urbana: Uma Análise do Setor Hoteleiro de Curitiba - PR. Dissertação (Mestrado em Geografia). Universidade Federal do Paraná, Curitiba, 2007.

PAN, C. M. Market concentration ratio analysis of the international tourist hotel industry in Taipei area. In: Tourism Management Research 2 (2), p. 57-66, 2002.

PARANÁ. Secretaria de Estado do Turismo. Demanda Turística de Curitiba (20002006). Curitiba, 2007.

PARANÁ. Secretaria de Estado do Turismo. Estudo da Demanda Turística de Foz do Iguaçu - PR (1995-2007). Curitiba, 2008a. 
PARANÁ. Secretaria de Estado do Turismo. Estudo da Demanda Turística de Cascavel - PR (2005-2007). Curitiba, 2008b.

PARANÁ. Secretaria de Estado do Turismo. Estudo da Demanda Turística LitoralPR (2006). Curitiba, 2008c.

PARANÁ. Secretaria de Estado do Turismo. Estudo da Demanda Turística de Londrina - PR (2005-2007). Curitiba, 2008d.

PARANÁ. Secretaria de Estado do Turismo. Estudo da Demanda Turística de Maringá - PR (2005-2007). Curitiba, 2008e.

PEREIRA, Y.; LUCENA, E. Estratégias adotadas pela Accor Hotels do Brasil entre 1974 e 2006. In: Turismo em Análise, São Paulo, v. 20, n. 1, p. 48-69, 2009.

PÍCCOLO, D. R. A entrada de capital internacional na rede hoteleira de Maringá: o caso do Hotel Ibis. Trabalho de Graduação (Bacharelado em Geografia) - Centro de Ciências Humanas, Artes e Letras, Universidade Estadual de Maringá, Maringá, 2008.

Dispersão Territorial das Redes Hoteleiras Internacionais para Cidades do Interior: o caso de Maringá/PR. In: Caminhos de Geografia, Uberlândia, v. 12, n. 17, p. 44-53, mar/2011.

PROSERPIO, R. O avanço das redes hoteleiras internacionais no Brasil. São Paulo: Aleph, 2007.

RIBEIRO, H. C. A Hotelaria na Cidade de Porto Alegre: gestão de redes e gestão familiar. Dissertação (Mestrado em Turismo). Universidade de Caxias do Sul, 2005.

ROSA, L. G. A dinâmica espacial dos serviços hoteleiros e o turismo de negócios e eventos em Campinas. Tese (Doutorado em Geografia). Instituto de Geociências e Ciências Exatas, Universidade Estadual Paulista, Rio Claro, 2009.

SANTOS, F. M. Uma análise histórico-espacial do setor hoteleiro no núcleo urbano central de Florianópolis. Dissertação (Mestrado em Turismo e Hotelaria). Centro de Educação de Balneário Camboriú, Universidade do Vale do Itajaí, Balneário Camboriú, 2007.

SANTOS, F. M.; PEREIRA, R. M. F. A. Análise histórico-espacial do setor hoteleiro no núcleo urbano central de Florianópolis - SC. Geosul, Florianópolis, v. 23, n. 46, p. 115-135, jul./dez., 2008.

SANTOS, M.; SILVEIRA, M. L. O Brasil: território e sociedade no início do século XXI. 10. ed. Rio de Janeiro: Record, 2008.

SILVA, A. M. P. O processo de reorganização espacial da hotelaria em Recife: concentração em Boa Viagem e marginalização da área central. Dissertação (Mestrado em Geografia). Universidade Federal de Pernambuco, Recife, 2007a. 
SILVA, L. C. R. da. Os meios de hospedagem em Salvador: distribuição espacial ao longo de sua história. Dissertação (Mestrado em Geografia). Universidade Federal da Bahia, Salvador, 2007b.

SPOLON, A. P. G. Chão de estrelas: hotelaria e produção imobiliária em São Paulo, 1995-2005. Dissertação (Mestrado em Arquitetura e Urbanismo). Faculdade de Arquitetura e Urbanismo, Universidade de São Paulo, São Paulo, 2006.

SPOSITO, M. E. B. O chão em pedaços: urbanização, economia e cidades no Estado de São Paulo. Tese (Livre Docência). Faculdade de Ciências e Tecnologia, Universidade Estadual Paulista, Presidente Prudente, 2004.

TELES, R. M. de S. Turismo urbano na cidade de São Paulo: o deslocamento do CBD e os seus reflexos na hotelaria. Tese (Doutorado em Ciências da Comunicação). Escola de Comunicação e Artes, Universidade de São Paulo, São Paulo, 2009.

VILLANUEVA RAMOS, S. E. A dinâmica da localização da hotelaria curitibana no período de 1966 a 2008. Tese (Doutorado em Geografia). Universidade Federal do Paraná, Curitiba, 2010.

WADA, E. K. Turismo de Negócios: viagens coorporativas, eventos e incentivos. In: PANOSSO NETTO, A.; ANSARAH, M. G. R. (Orgs.). Segmentação do Mercado Turístico: estudos, produtos e perspectivas. Barueri: Manole, 2009.

Recebido em: 24-04-2102.

Aprovado em: 24-05-2012. 